\title{
Aptamer-modified gold nanoparticles for targeting breast cancer cells through light scattering
}

\author{
Yu-Fen Huang · Yang-Wei Lin · Zong-Hong Lin • \\ Huan-Tsung Chang
}

Received: 18 September 2007/ Accepted: 18 May 2008/Published online: 5 June 2008

(C) Springer Science+Business Media B.V. 2008

\begin{abstract}
In this study, we demonstrated the potential use of nucleic acid ligand (aptamers) conjugated gold nanoparticles (AuNPs) for cancer cell detection. Through specific binding of the aptamers toward platelet-derived growth factor (PDGF), MDA-MB231 and Hs578T cells (cancer cells) that over-express PDGF, interact with Apt-AuNPs to a greater extent than do H184B5F5/M10 cells (normal cells). These results were confirmed through inductively coupled plasma mass spectrometry measurements of the gold ion concentrations within these cells. Aggregation of the Apt-AuNPs in the cytoplasm of the cancer cells led to the generation of an intense scattered light upon photo-illumination; this phenomenon allows the differentiation of cancer cells from normal cells using a dark field optical microscope. The presence of AptAuNPs suppressed the proliferation of MDA-MB-231 cancer cells, but not H184B5F5/M10 cells.
\end{abstract}

Keywords Aptamer - Gold nanoparticles · Breast cancer cells · Imaging · Proliferation · Nanomedicine

Y.-F. Huang · Y.-W. Lin · Z.-H. Lin · H.-T. Chang ( $₫)$ Department of Chemistry, National Taiwan University, 1, Section 4, Roosevelt Road, Taipei 106, Taiwan, ROC e-mail: changht@ntu.edu.tw

H.-T. Chang

Department of Natural Science Education, National

Taitung University, Taitung, Taiwan, ROC

\section{Introduction}

A number of monodisperse nanoparticles (NPs) have been applied to drug delivery, cancer cell diagnostics, and therapeutics (Fukumori and Ichikawa 2006; Jain 2005; Pissuwan et al. 2006; Zhi et al. 2006). Owing to their high degrees of contrast and size-dependent optical properties, bioconjugated gold nanoparticles (AuNPs) (Chen et al. 2005; Sokolov et al. 2003b) and quantum dots (Alivisatos et al. 2005) have become useful materials for cell imaging, providing anatomic details of cells and tissue architectures that are important for cancer diagnostics. Although quantum dots offer the advantages of optical and chemical stability, narrow emission profiles, and size-dependent emission properties when excited at the same wavelength, their applications are somewhat limited by their potential toxicity (Chan and Nie 1998). In contrast, colloidal AuNPs are highly suitable for cell imaging because of their ease of preparation and bioconjugation, high contrast, large absorption coefficients, and potential non-cytotoxicity (El-Sayed et al. 2005; Sokolov et al. 2003b). For example, antibody-bioconjugated AuNPs have been used for specific staining of targeted cells and monitored by electron microscopy (Horisberger 1981).

Surface plasmon resonance (SPR) results show that AuNPs exhibit strong extinction properties at the visible-to-near-infrared region, depending on their sizes and shapes (Hu et al. 2006). SPR is a result of the coherent collective oscillation of the conduction 
band electrons in small metallic particles under irradiation with light. Light scattered by the AuNPs is strong and stable. This property allows the detection of $10^{-16} \mathrm{M}$ AuNPs with an average diameter of $118 \mathrm{~nm}$ (Yguerabide and Yguerabide 1998), and the targeted imaging of cancer cells through the combined use of bioconjugated AuNPs and confocal scanning optical microscopy (Sokolov et al. 2003a, b), multiphoton plasmon resonance microscopy (Yelin et al. 2003), or dark-field microscopy (ElSayed et al. 2005). In addition, plasmon resonance, in response to incoming light, causes local heating or the release of therapeutic molecules that may destroy or cure diseased tissues, respectively. For example, antibody-conjugated gold nanoshells and nanorods have been employed to selectively kill cancer cells (Huang et al. 2006; Loo et al. 2005).

In this paper, we have prepared aptamer-bioconjugated AuNPs (Apt-AuNPs) and described their use as novel contrast agents for the detection of cancer cells under a simple and inexpensive conventional darkfield optical microscope (DFM). Aptamers are nucleotides typically having lengths ranging between 15 and 70 bases. They can be selected by a process referred to as systematic evolution of ligands by exponential enrichment (SELEX) from a pool of DNA or RNA by repetitive binding of the oligonucleotides to target molecules (Green et al. 1990; Tuerk and Gold 1990). They are reliable affinity substitutes for antibodies with benefits derived mainly from their temperature stability and ease of production. Although advances in SELEX techniques have resulted in an increase in the number of applications of DNA and RNA aptamers in various areas of biotechnology, e.g., sensing, purification, and therapeutic applications (Hamula et al. 2006; Proske et al. 2005; Tombelli et al. 2005), very few reports describe the use of aptamers and NPs for selective targeting of cancer cells (Farokhzad et al. 2006; Herr et al. 2006). Representative applications include cell imaging and drug delivery using fluorophore-labeled (Farokhzad et al. 2004) and drug-encapsulated (Farokhzad et al. 2006) NPs that had been functionalized with various aptamers.

In this study, we prepared Apt-AuNPs for selective targeting of cancer cells. In these systems, the AuNPs act as a signaling moiety and the aptamers act as recognition units that have a high affinity $\left(K_{d}=0.1-\right.$ $10 \mathrm{nM}$ ) toward platelet-derived growth factor (PDGF)
(Green et al. 1996). PDGF, which can stimulate the division and proliferation of cells through binding with receptors on the cell membrane surface, is a ubiquitous mitogen and chemotactic factor for many connective tissue cells (Heldin and Westermark 1999). The expression of PDGF in normal cells occurs at undetectable or low levels, while in cells with malignancies and developmental abnormalities, it is over-expressed (Bronzert et al. 1987; Leitzel et al. 1991). PDGF induced aggregation of the AptAuNPs in the cells led to a remarkably diverse range of scattering images. In addition, the Apt-AuNPs prohibited the metabolic activity and proliferation of cancer cells, but had no determinant effect on normal cells.

\section{Experimental section}

\section{Chemicals}

Sodium tetrachloroaurate(III) dehydrate was obtained from Sigma (St. Louis, MO, USA). Trisodium citrate and 6-mercapto-1-hexanol were purchased from Aldrich (Milwaukee, WI, USA). The 5'-thiol-modified aptamer having the sequence $5^{\prime}$-CAG GCT ACG GCA CGT AGA GCA TCA CCA TGA TCC TG- $3^{\prime}$ was purchased from Integrated DNA Technology Inc. (Coralville, IA, USA). Recombinant human PDGFs were purchased from R\&D Systems Inc. (Minneapolis, MN, USA). PDGFs were dissolved in $4.0 \mathrm{mM}$ $\mathrm{HCl}$ containing $0.1 \%$ bovine serum albumin (BSA). BSA, trypsinogen, and lysozyme were obtained from Sigma.

\section{Synthesis of 32-nm AuNPs}

Trisodium citrate $(1 \% ; 0.5 \mathrm{~mL})$ was added rapidly to an aliquot of $0.01 \% \mathrm{NaAuCl}_{4}(50.0 \mathrm{~mL})$ that was heated at $100{ }^{\circ} \mathrm{C}$ under reflux (Frens 1973; Grabar et al. 1995). Heating under reflux was continued for an additional $8 \mathrm{~min}$, during which time the color changed to deep red. The solution was set aside to cool to room temperature; it was stable for at least 6 months. The as-prepared AuNP solution had a maximum absorbance at $528 \mathrm{~nm}$ (Cintra 10e, GBC, Victoria, Australia), which is a characteristic surface plasmon resonance band for 32-nm AuNPs. TEM images (H-7100 TEM, Hitachi, Tokyo, Japan) also 

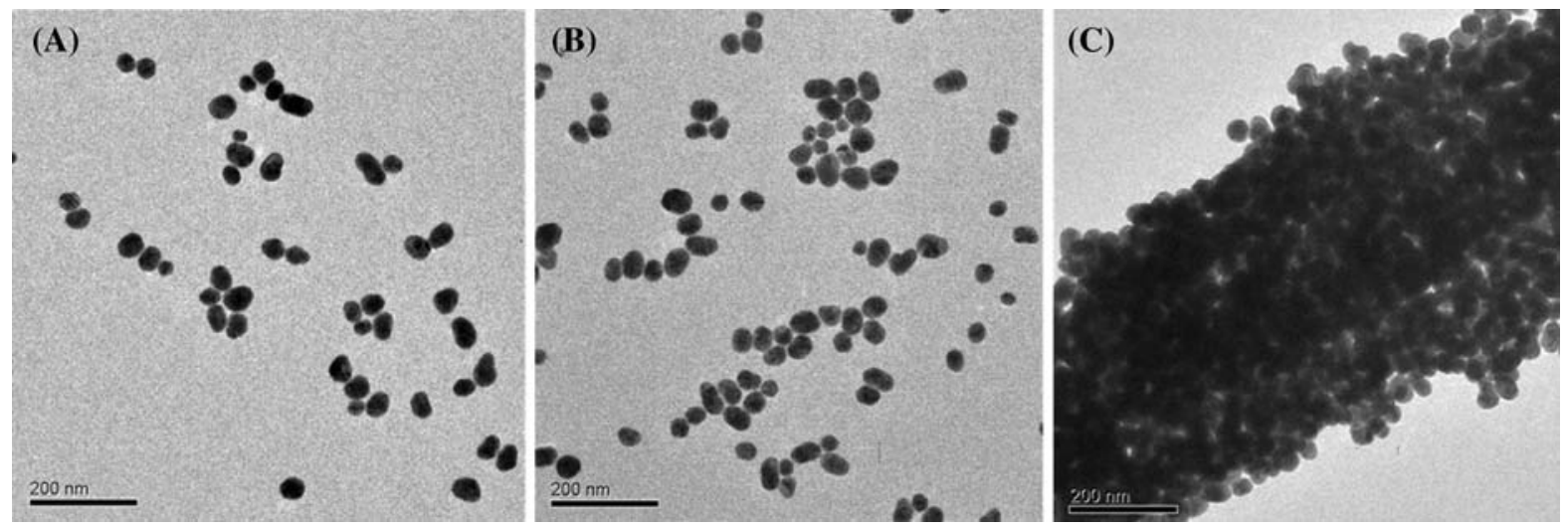

Fig. 1 TEM images of (a) AuNPs and Apt-AuNPs (b) in the absence and (c) in the presence of $1.0 \mathrm{nM}$ PDGF

confirmed that the diameters of the AuNPs were 32 $( \pm 1) \mathrm{nm}$ (Fig. 1a). Herein, the concentration of the as-prepared 32-nm-diameter AuNPs is denoted as $1 \times$; this value corresponds to a concentration of ca. $0.3 \mathrm{nM}$ (Jana et al. 2001).

\section{Preparation of Apt-AuNPs}

The thiol-modified aptamer was attached to the AuNPs according to the method modified from literature (Storhoff et al. 1998). The 5'-thiol-modified aptamer was received in a disulfide form $\left[\mathrm{HOCH}_{2}\left(\mathrm{CH}_{2}\right)_{5} \mathrm{~S}\right.$-S5 -oligo], protected by a mercaptohexanol group. These aptamers were reacted directly with the AuNPs through attachment of both the $\mathrm{HOCH}_{2}\left(\mathrm{CH}_{2}\right)_{5} \mathrm{~S}$ and oligo-S units onto the AuNP surface; the bioconjugate is denoted as "Apt-AuNP." A $0.8 \mathrm{~mL}$ aliquot of aqueous AuNP solution was mixed with $0.2 \mathrm{~mL}$ of $0.5 \mu \mathrm{M}$ thio-aptamer to obtain a final concentration of $0.2 \mathrm{nM}$ AuNPs and $0.1 \mu \mathrm{M}$ aptamers. After reaction for $24 \mathrm{~h}$ at room temperature, the mixture was equilibrated with $0.1 \% \mathrm{BSA}$ for $60 \mathrm{~min}$ at room temperature before conducting two centrifuge/wash cycles $(6,000 \mathrm{rpm}, 5 \mathrm{~min})$ to remove any excess thiolaptamer. Following the removal of the supernatants, the oily precipitates were resuspended in $4.0 \mathrm{mM}$ trisodium citrate solution containing $0.1 \% \mathrm{BSA}$ and then stored in a refrigerator $\left(4^{\circ} \mathrm{C}\right)$. BSA was present to prevent aggregation of the Apt-AuNPs in the serumfree media. In order to determine the number of aptamers on each Apt-AuNP, a $10.0 \mu \mathrm{L}$ aliquot of 1.0 M 2-mercaptoethanol was added to displace the aptamers from the surfaces of the Apt-AuNPs $(0.20 \mathrm{nM}, 990.0 \mu \mathrm{L})$. The displaced aptamers in the supernatant were labeled with oligreen (Quant-iT OliGreen ssDNA reagent, Molecular Probe, Eugene, Oregon, USA). Fluorescence intensity measurements at $538 \mathrm{~nm}$ show that the surface concentration of aptamers is ca. 200 aptamers per AuNP (Storhoff et al. 1998). For the control experiment, mercaptohexanolmodified AuNPs (MH-AuNPs) were used and protected with BSA prior to cell incubation.

Cells incubated in media with/without AuNPs or Apt-AuNPs

One normal epithelial cell line, H184B5F5/M10 (human mammary cells), and three cancer epithelial cell lines, MDA-MB-231, Hs578T, and MCF-7 (human breast adenocarcinoma), were obtained from American Type Culture Collection (ATCC, Rockville, MD) and tested in this study. MDA-MB-231 cancer cells and H184B5F5/M10 cells were cultured in Minimum essential medium (Gibco BRL, New York, USA) containing $10 \%$ fetal bovine serum (FBS; Gibco). Hs578T cancer cells were grown in Dulbecco's modified Eagle's medium (Gibco) and MCF-7 cancer cells were grown in Minimum essential medium Eagle (Gibco); both of these media were supplemented with $10 \% \mathrm{FBS}$ and $0.01 \mathrm{mg} / \mathrm{mg}$ bovine insulin (Gibco). Cells were grown at $37{ }^{\circ} \mathrm{C}$ in a humidified atmosphere with $5 \% \quad \mathrm{CO}_{2}$ (in air). The medium was changed every 3 days. At ca. $80 \%$ confluency, the cells were trypsinized with trypsin/ EDTA solution ( $0.25 \%$ trypsin, $1 \mathrm{mM}$ EDTA) for 5$10 \mathrm{~min}$ at $37^{\circ} \mathrm{C}$ to detach the cells for reseeding and growing in the new culture dishes at a density of ca. $10^{5}$ cells per culture dish. After $24 \mathrm{~h}$, the growth 
medium was removed and the cells were washed three times with phosphate-buffered saline (PBS) solution. The cells were incubated in serum-free media (1.0 mL) each containing $1.3 \mathrm{pM}$ AuNPs, AptAuNPs, and MH-AuNPs for $3 \mathrm{~h}$ to minimize nonspecific adsorption of serum proteins onto the particle surfaces.

Dark field microscopy (DFM) and transmission electron microscopy (TEM) imaging

An Olympus IX70 inverted microscope (Tokyo, Japan) was used to construct the scattering imaging. A 100-W halogen lamp in conjunction with a highnumerical-aperture dark-field condenser (numeric aperture: 1.2-1.4; U-DCW, Olympus) was used to illuminate the AuNPs. The scattering signals were collected using a $20 \times$ objective (numeric aperture: 0.4). The wide-field images were collected using a digital color camera (Coolpix 5400, Nikon, Tokyo, Japan) attached to the side port of the microscope. For TEM imaging, excess particles were removed by conducting a five-cycle washing/centrifugation cleaning process. The cells were then fixed in $2.5 \%$ glutaraldehyde that was prepared in $0.1 \%$ sodium cacodylate buffer. The samples were subsequently post-fixed and stained with $1 \%$ aqueous $\mathrm{OsO}_{4}$ and then dehydrated using a series of ethanol solutions (50\%, 70\%, 80\%, 90\%, and 95\% for $10 \mathrm{~min}$ each; and twice with $100 \%$ for $15 \mathrm{~min}$ ) prior to being resinembedded. Thin sections containing the cells were placed on grids prior to TEM measurement at $75 \mathrm{kV}$.

Inductively coupled plasma mass spectrometry (ICP-MS) measurements

ICP-MS (Elan 6000, Perkin-Elmer, Norwalk, CT) measurements were performed to determine the concentrations of the AuNPs and Apt-AuNPs within cells. Different types of cells were incubated for $3 \mathrm{~h}$ in media $(1.0 \mathrm{~mL})$ with/without $1.3 \mathrm{pM}$ Apt-AuNPs or AuNPs. After washing five times with PBS, the cells were harvested through trypsinization and then dissolved in $2 \% \mathrm{HNO}_{3}$ aqueous solution $(1.5 \mathrm{~mL})$. The cells were disrupted by sonication for $20 \mathrm{~min}$ at $0{ }^{\circ} \mathrm{C}$ and then the concentrations of the gold ions were determined using ICP-MS. The number of gold ions (atoms) was then converted to the number of AuNPs by using the following relationship: number of 32-nm AuNPs per $\mathrm{mL}=\left\{\left[4 / 3 \pi r^{3} \times d /\right.\right.$ atomic weight of $\left.\mathrm{Au}] \times 6.02 \times 10^{23}\right\}$ per $\mathrm{mL}=$ number of $\mathrm{Au}$ atoms per $\mathrm{mL} / 1,012,401$, in which $r$ is the radius of AuNP and $d\left(19.3 \mathrm{~g} / \mathrm{cm}^{3}\right)$ is the density of Au (Liu et al. 2007).

AlamarBlue assay

AlamarBlue assays (colorimetric methods) were carried out to investigate the proliferation and metabolic activity of cells. For living cells, mitochondrial reductase enzymes are active and reduce AlamarBlue (AbD Serotec Ltd., Kidlington, Oxford, UK) to form a product that has a different color from the AlamarBlue. By measuring the absorbance at $570 \mathrm{~nm}$ with background subtraction at $650 \mathrm{~nm}$, the vitality of the cells in the culture was determined according to a linear plot of absorbance versus cell numbers ranging from 5,000 to 40,000 cells $/ \mathrm{mL}$. These experiments were repeated three times and by using a $t$-test, the results from three different trials were not different based on $95 \%$ confidence.

\section{Results and discussion}

DFM measurements of cancer and normal cells

In order to determine a procedure for readily differentiating cancer and normal cells in the study, we conducted DFM measurements of cells in the presence of Apt-AuNPs. To achieve high sensitivity, it was necessary to optimize the size of the AptAuNPs. Although smaller-sized Apt-AuNPs are transported across the cytoplasmic membrane more easily, their scattering of light is weaker than that of larger-sized Apt-AuNPs. In addition, we found that the faintly greenish light that scattered from AptAuNPs having sizes below $26 \mathrm{~nm}$ was not readily resolved from the light scattered from the cellular organelles. In this study, we found that the use of 32nm Apt-AuNPs was optimal. We point out that light scattering undergoes red shift and become stronger upon increasing the size of AuNPs. Through thiolmodification, we prepared the bioconjugated AptAuNPs that exhibit a slightly higher SPR absorption ( $\sim 0.03$ a.u.) than that of the AuNPs, mainly due to changes in the dielectric constant of the surrounding AuNP surfaces. Apt-AuNPs were also characterized 

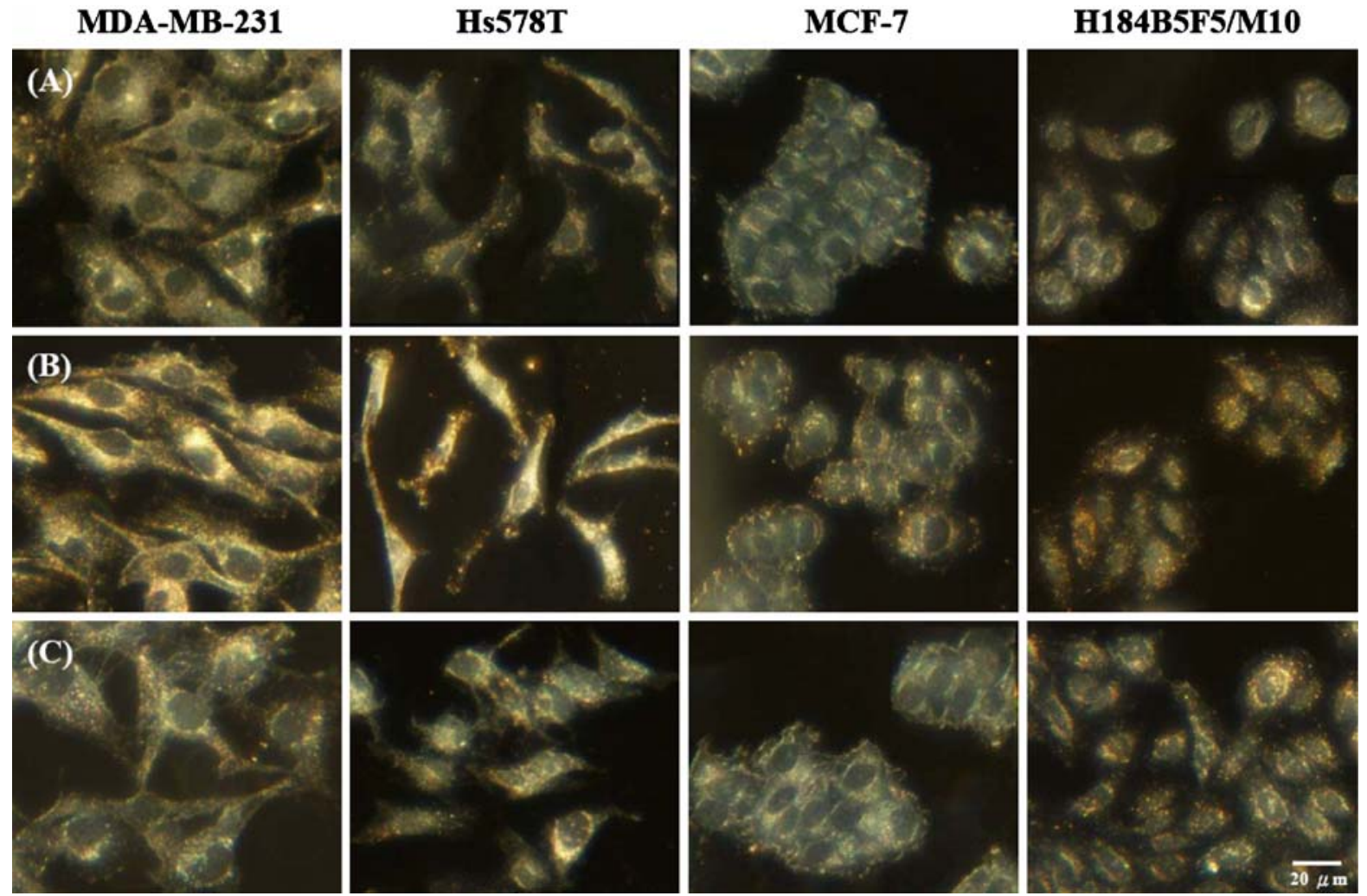

Fig. 2 Light scattering images of three sets of cancer cells (MDA-MB-231, Hs578T, and MCF-7) and one set of normal cells (H184B5F5/M10) cultured (a) in the absence Apt-AuNPs,

by TEM, while no changes in the sizes and no aggregation occurred (Fig. 1b).

Figure 2a exhibits the light scattering images of cancer cells of different morphologies (MDA-MB231, Hs578T, and MCF-7) and a non-cancer normal epithelial cell line (H184B5F5/M10) that had not been incubated with the Apt-AuNPs. MDA-MB-231 cancer cells have similar shapes to those of Hs578T cancer cells, but the former are nearly twice as large as the latter. The MCF-7 (cancer) and H184B5F5/ M10 cells have round shapes that are different from those of the other two types of cells. Some areas within the cells display dim greenish spots in all cell lines, which is likely due to autofluorescence and scattering from the organelles that are distributed in the cells' cytoplasms and membranes (El-Sayed et al. 2005).

After incubation with the Apt-AuNPs, the incorporated NPs led to the appearance of spotted patterns within the cytoplasms of the MDA-MB-231 and

and (b, c) in the presence of (b) Apt-AuNPs and (c) MHAuNPs (control) for $3 \mathrm{~h}$ at $37^{\circ} \mathrm{C}$ in a humidified atmosphere with $5 \% \mathrm{CO}_{2}$ (in air)

Hs578T cancer cells. Aggregation of the Apt-AuNPs resulted in bright yellowish scattered spots that allow the ready identification of individual cells (Fig. 2b). On the contrary, only small and faintly reddish dots occurred within the MCF-7 (cancer) and H184B5F5/ M10 cells, indicating that less extent of aggregation occurred in those cells. This approach is quite sensitive: the culture media contained the Apt-AuNPs at concentrations of only ca. $1.3 \mathrm{pM}$. Aggregation of the Apt-AuNPs occurred mainly as a result of specific binding through cross-linking with the PDGF (Huang et al. 2005) present in the cytoplasm of the cells; this result is supported by the fact that only a slight degree of aggregation occurred in the MCF-7 (cancer) and H184B5F5/M10 cells, which include lower contents of PDGF. The PDGF concentrations determined in MDA-MB-231 and MCF-7 were 5.0 and $1.0 \mathrm{ng} / \mathrm{mL}$, respectively (Bronzert et al. 1987). In contrast, for the control experiment, we observed no significant differences between the scattering images of the four 
Fig. 3 TEM images of Apt-AuNPs in (a) MDAMB-231 cancer cells and (b) H184B5F5/M10 cells. The Apt-AuNP aggregates are marked with black arrows. Cells were exposed to the Apt-AuNPs for $3 \mathrm{~h}$, fixed with osmium tetroxide, sectioned, and then visualized using a Hitachi H-7100 electron microscope
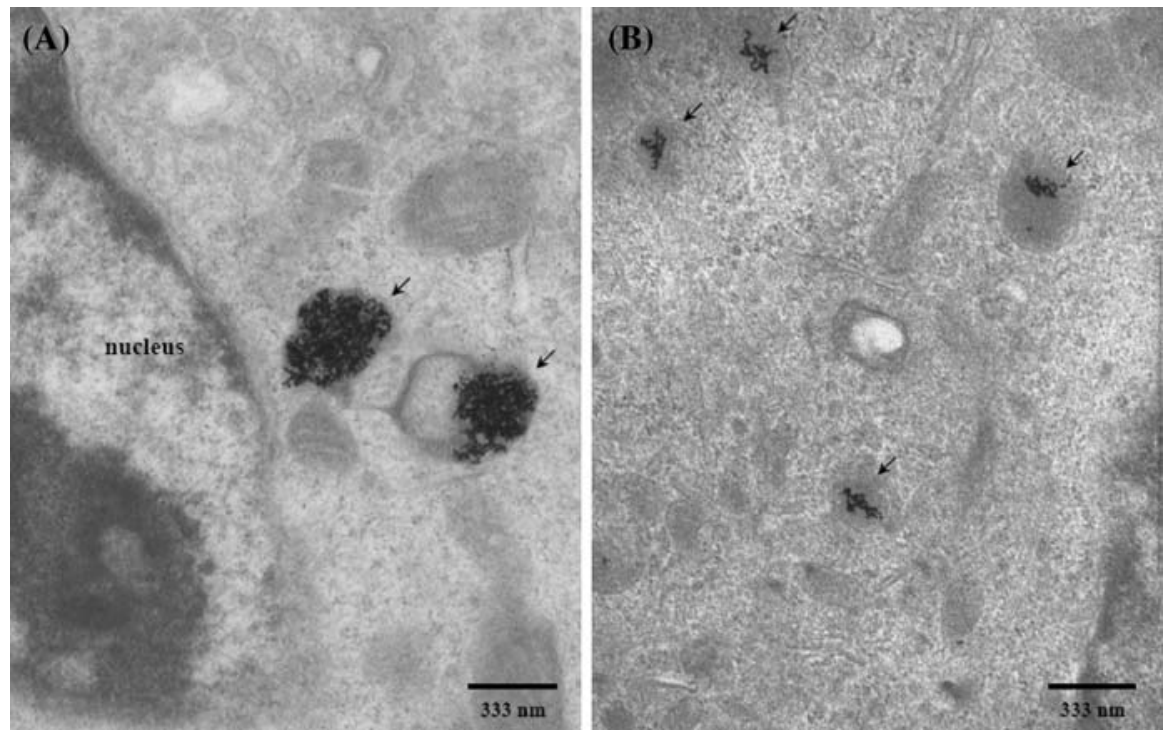

types of cells in the absence and presence of $\mathrm{MH}$ AuNPs (cf. Fig. 2a and c). This finding suggests that specific interactions occurred between the Apt-AuNPs and the PDGF.

The amount of Apt-AuNPs within a cell

We used TEM to gain further evidence for the PDGFinduced aggregation of Apt-AuNPs within the MDAMB-231 (cancer) and H184B5F5/M10 cells. The TEM images in Fig. 3 reveal that Apt-AuNPs accumulated predominantly within the random area of cytoplasm in these two cells. Because the NPs used in this study were too large to cross the nuclear membrane through nuclear pores $(<30 \mathrm{~nm})$, we observed no light scattering from the nucleus (Tkachenko et al. 2003). TEM images also suggested that aggregation of the Apt-AuNPs inside the MDA-MB-231 cancer cells (Fig. 3a) occurred to a greater extent than that inside the H184B5F5/M10 cells (Fig. 3b). This finding is consistent with the results of the DFM measurements in Fig. 2b; larger aggregates scattered light more strongly.

As indicated in Fig. 2b, the amounts of Apt-AuNPs incorporated in the MCF-7 cancer cells and the H184B5F5/M10 cells were lower than those in the MDA-MB-231 and Hs578T cancer cells. ICP-MS measurements support these DFM results: the amounts of Apt-AuNPs within the four types of cells displayed in Fig. 4 decreased in the order MDA-MB-231 (cancer) $>$ Hs578T (cancer) $>$ H184B5F5/M10 > MCF-7

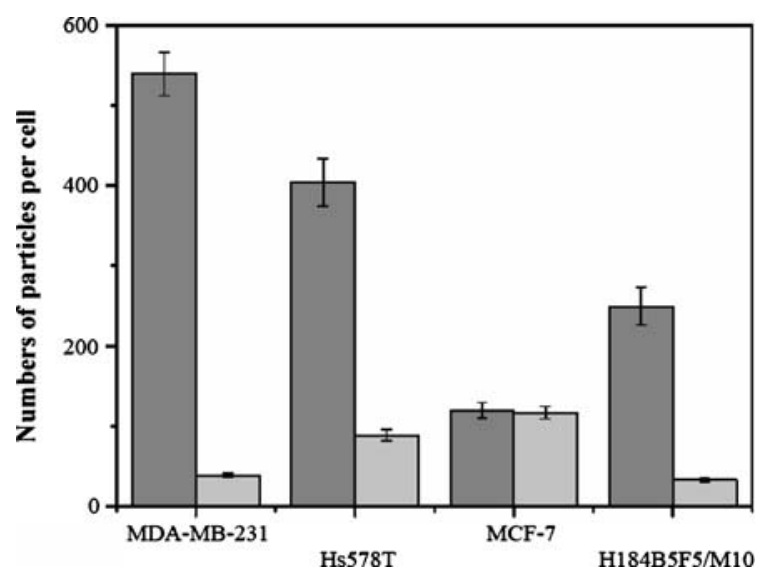

Fig. 4 Contents of Apt-AuNPs (dark gray) and MH-AuNPs (control, light gray) in four types of breast cells. The concentrations of gold ions were determined using ICP-MS

(cancer). The amount of Apt-AuNPs in the H184B5F5/ M10 cells was greater than that in the MCF-7 cancer cells; this result was unexpected because it has been reported that most cancer cells express relatively higher amounts of PDGF (Bronzert et al. 1987; Peres et al. 1987). Nevertheless, Coltrera et al. (1995) demonstrated that the cytoplasmic expression of PDGF can be detected in both benign and malignant breast tissues.

In order to further support our contention that the amount of Apt-AuNPs within a cell is correlated to the amount of PDGF present, we separately cultured the cells in a medium containing PDGF $(1.0 \mathrm{nM})$ prior to adding the Apt-AuNPs. The PDGF concentrations before and after treatment were about 0.2 and 


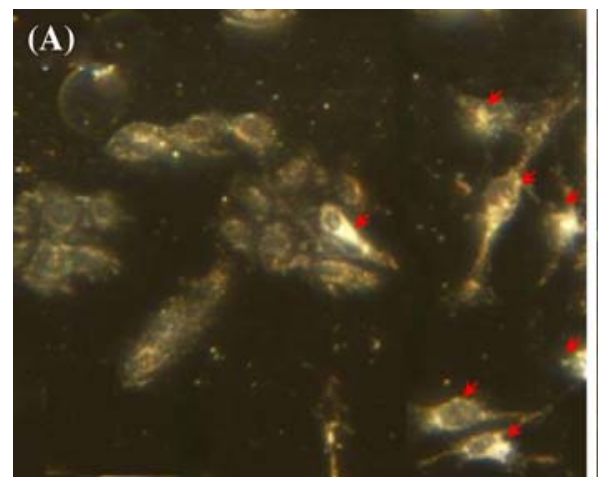

Fig. 5 DFM images of mixtures of cancer MDA-MB-231 and normal H184B5F5/M10 cells after incubation for $3 \mathrm{~h}$ in a medium containing Apt-AuNPs. The original ratios of the cell

$1.0 \mathrm{nM}$, respectively. As expected, greater amounts of Apt-AuNPs entered the treated cells; the amount of Apt-AuNPs incorporated in the MDA-MB-231 cancer cells cultured in the medium containing additional PDGF (2,689 Apt-AuNPs per cell) was ca. 5-fold higher than that of the untreated cells (540 AptAuNPs per cell). We observed no differences in the amounts of Apt-AuNPs incorporated when the cell culture media contained other proteins, such as BSA, trypsinogen, and lysozyme (within the random error of \pm 30 Apt-AuNPs per cell).

\section{Differentiation cancer cells by Apt-AuNPs}

In order to test the ability of the Apt-AuNPs to differentiate normal cells from some types of cancer cells, we cultured MDA-MB-231 cancer cells in the presence of H184B5F5/M10 cells and then analyzed these mixtures using DFM. One representative image (Fig. 5a) demonstrates that the combination of DFM and Apt-AuNPs is a practical tool for the identification of cancer cells. The bright cells that are highlighted by red arrows are MDA-MB-231 cancer cells; the others are H184B5F5/M10 cells. We were able to differentiate cancer cells from normal ones even at a cell number ratio of 1:100 (Fig. 5b). These results clearly suggest that the present approach has great potential for use in cancer diagnosis.

\section{Effect of Apt-AuNPs on cell proliferation}

By counting cell numbers, we found that incorporation of the Apt-AuNPs into the MDA-MB-231 cancer cells suppressed their growth, but had no effect on the

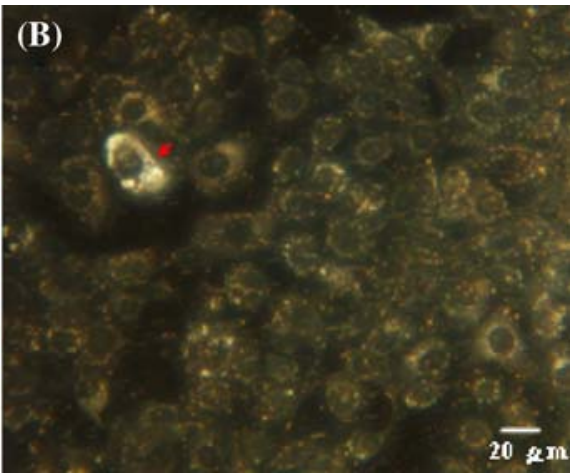

numbers of MDA-MB-231 and H184B5F5/M10 were (a) 1:1 and (b) 1:100. The MDA-MB-231 cancer cells are highlighted with red arrows; the other cells are H184B5F5/M10 cells

growth of the H184B5F5/M10 cells. The TEM images in Fig. 3 indicate clearly that the Apt-AuNPs resided within the cytoplasm of the MDA-MB-231 cancer cells, suggesting that it was the specific binding of the Apt-AuNPs toward the PDGF that suppressed the growth of these cells (Floege et al. 1999). We also performed AlamarBlue assays to determine the proliferation and metabolic activity of the two types of cells. Figure 6 indicates that the AptAuNPs suppressed the proliferation of MDA-MB-231 cancer cells by ca. $20 \%$, but had a less-than- $1 \%$ effect on the H184B5F5/M10 cells.

In this study, we calculated the percentages of cell proliferation from the absorbance ratios of the AlamarBlue assays for the cells cultured for $3 \mathrm{~h}$ in

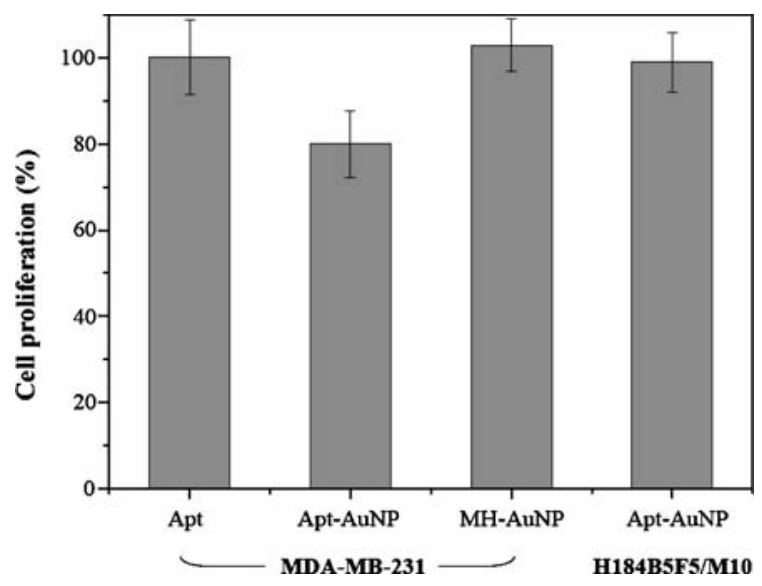

Fig. 6 AlamarBlue assays used to determine the cell proliferation percentages $(\%)$ of cancer MDA-MB-231 and normal H184B5F5/M10 cells that had been incubated for $3 \mathrm{~h}$ in media containing $0.3 \mathrm{nM}$ PDGF aptamers and $1.3 \mathrm{pM}$ Apt-AuNPs or 1.3 pM MH-AuNPs (control) 
the presence of MH-AuNPs (control) or Apt-AuNPs to those cultured for $3 \mathrm{~h}$ in the absence of MH-AuNPs (control) and Apt-AuNPs. We note that the effective concentration of the Apt-AuNPs was ca. 1,000-fold lower than that reported for other gold-based NP systems (Bhattacharya et al. 2004; Pernodet et al. 2006; Tsoli et al. 2005). The aptamer itself (i.e., not bound to AuNPs) had no suppressive effect on the proliferation of the MDA-MB-231 cancer cells, mainly because it possesses a negative charge and could not migrate across the cell membranes efficiently (Thomas and Klibanov 2003). We also conclude that the MH-AuNPs (control) had no suppressive effect on the proliferation of the two types of cells (Connor et al. 2005; de la Fuente et al. 2006).

Although the Apt-AuNPs slightly suppressed the proliferation of the H184B5F5/M10 cells, this effect was trivial when compared with that of the MDAMB-231 cancer cells. We also found that the suppression effect of the Apt-AuNPs increased upon increasing their concentration and incubation time, reaching saturation at $1.3 \mathrm{pM}$ and $3 \mathrm{~h}$, respectively. Because nonspecific adsorption occurs at a much slower rate, we expected that the suppression efficiency of the Apt-AuNPs would increase if fresh AptAuNPs were added. In order to support this reasoning, we added fresh Apt-AuNPs (1.3 pM) every $45 \mathrm{~min}$ (four times) to MDA-MB-231 cancer cells. After incubation for $3 \mathrm{~h}$, the suppression of the proliferation of MDA-MB-231 cancer cells was ca. $40 \%$. Under similar conditions, the suppression of the proliferation of H184B5F5/M10 cells was still less than $1 \%$.

\section{Conclusion}

DFM measurements using Apt-AuNPs are useful for the identification of some types of cancer cells among normal cells. PDGF-induced aggregation of AptAuNP, led to a high-intensity scattered light that had a different color from that scattered from the original Apt-AuNPs and cell organelles. When comparing immunostaining, our approach offers advantages of lower cost and minimum matrix interference. We also point out that fluorescence decay under light illumination is problematic when applying fluorescence measurements. We also found that the Apt-AuNPs suppressed the growth of cancer cells, but had no detrimental effect on normal cells. These results suggest that aptamer-bioconjugated NPs may be suitable for use in cancer therapy. At present, we are focusing on the preparation of Au nanorods that are bioconjugated with various aptamers for cancer therapy. It is our belief that the proliferation of cancer cells will be suppressed to a great extent when they are selectively irradiated under light.

Acknowledgements This study was supported by the National Science Council (NSC 95-2113-M-002-026-MY3, NSC 96-2627-M-002 -013 and NSC 96-2627-M-002 -014) of Taiwan. We are grateful to Messrs Ching-Yen Lin and ChihYuan Tang of the Instrumentation Center, National Taiwan University, for their assistance in conducting the TEM measurements.

\section{References}

Alivisatos AP, Gu W, Larabell C (2005) Quantum dots as cellular probes. Annu Rev Biomed Eng 7:55-76

Bhattacharya R et al (2004) Gold nanoparticles inhibit VEGF165-induced proliferation of HUVEC cells. Nano Lett 4(12):2479-2481

Bronzert DA et al (1987) Synthesis and secretion of plateletderived growth-factor by human-breast cancer cell-lines. Proc Natl Acad Sci USA 84(16):5763-5767

Chan WCW, Nie S (1998) Quantum dot bioconjugates for ultrasensitive nonisotopic detection. Science 281(5385): 2016-2018

Chen J et al (2005) Gold nanocages: bioconjugation and their potential use as optical imaging contrast agents. Nano Lett 5(3):473-477

Coltrera MD, Wang J, Porter PL, Gown AM (1995) Expression of platelet-derived growth-factor B-chain and the plateletderived growth-factor receptor-beta subunit in human breast-tissue and breast-carcinoma. Cancer Res 55(12): 2703-2708

Connor EE, Mwamuka J, Gole A, Murphy CJ, Wyatt MD (2005) Gold nanoparticles are taken up by human cells but do not cause acute cytotoxicity. Small 1(3):325-327

de la Fuente JM, Berry CC, Riehle MO, Curtis ASG (2006) Nanoparticle targeting at cells. Langmuir 22(7):3286-3293

El-Sayed IH, Huang X, El-Sayed MA (2005) Surface plasmon resonance scattering and absorption of anti-EGFR antibody conjugated gold nanoparticles in cancer diagnostics: applications in oral cancer. Nano Lett 5(5):829-834

Farokhzad OC et al (2004) Nanopartide-aptamer bioconjugates: a new approach for targeting prostate cancer cells. Cancer Res 64(21):7668-7672

Farokhzad OC et al (2006) Targeted nanoparticle-aptamer bioconjugates for cancer chemotherapy in vivo. Proc Natl Acad Sci USA 103(16):6315-6320

Floege J et al (1999) Novel approach to specific growth factor inhibition in vivo: antagonism of platelet-derived growth factor inGlomerulonephritis by aptamers. Am J Pathol 154(1):169-179 
Frens G (1973) Controlled nucleation for regulation of particlesize in monodisperse gold suspensions. Nat Phys Sci 241(105):20-22

Fukumori Y, Ichikawa H (2006) Nanoparticles for cancer therapy and diagnosis. Adv Powder Technol 17(1):1-28

Grabar KC, Freeman RG, Hommer MB, Natan MJ (1995) Preparation and characterization of Au colloid monolayers. Anal Chem 67(4):735-743

Green LS et al (1996) Inhibitory DNA ligands to plateletderived growth factor B-chain. Biochemistry 35(45):14413-14424

Green R, Ellington AD, Szostak JW (1990) In vitro geneticanalysis of the tetrahymena self-splicing intron. Nature 347(6291):406-408

Hamula CLA, Guthrie JW, Zhang H, Li X-F, Le XC (2006) Selection and analytical applications of aptamers. TracTrends Anal Chem 25(7):681-691

Heldin C-H, Westermark B (1999) Mechanism of action and in vivo role of platelet-derived growth factor. Physiol Rev 79(4):1283-1316

Herr JK, Smith JE, Medley CD, Shangguan D, Tan W (2006) Aptamer-conjugated nanoparticles for selective collection and detection of cancer cells. Anal Chem 78(9):29182924

Horisberger M (1981) Colloidal gold-a cytochemical marker for light and fluorescent microscopy and for transmission and scanning electron-microscopy. Scan Electron Micros II:9-32

Hu M et al (2006) Gold nanostructures: engineering their plasmonic properties for biomedical applications. Chem Soc Rev 35(11):1084-1094

Huang C-C, Huang Y-F, Cao Z, Tan W, Chang H-T (2005) Aptamer-modified gold nanoparticles for colorimetric determination of platelet-derived growth factors and their receptors. Anal Chem 77(17):5735-5741

Huang X, El-Sayed IH, Qian W, El-Sayed MA (2006) Cancer cell imaging and photothermal therapy in the near-infrared region by using gold nanorods. J Am Chem Soc 128(6):2115-2120

Jain KK (2005) Nanotechnology-based drug delivery for cancer. Technol Cancer Res Treat 4(4):407-416

Jana NR, Gearheart L, Murphy CJ (2001) Seeding growth for size control of 5-40 nm diameter gold nanoparticles. Langmuir 17(22):6782-6786

Leitzel K et al (1991) Elevated plasma platelet-derived growthfactor-B-chain levels in cancer-patients. Cancer Res 51(16):4149-4154

Liu X, Atwater M, Wang J, Huo Q (2007) Extinction coefficient of gold nanoparticles with different sizes and different capping ligands. Colloids Surf B Biointerfaces 58(1):3-7

Loo C, Lowery A, Halas N, West J, Drezek R (2005) Immunotargeted nanoshells for integrated cancer imaging and therapy. Nano Lett 5(4):709-711
Peres R, Betsholtz C, Westermark B, Heldin C-H (1987) Frequent expression of growth-factors for mesenchymal cells in human mammary-carcinoma cell-lines. Cancer Res 47(13):3425-3429

Pernodet $\mathrm{N}$ et al (2006) Adverse effects of citrate/gold nanoparticles on human dermal fibroblasts. Small 2(6):766773

Pissuwan D, Valenzuela SM, Cortie MB (2006) Therapeutic possibilities of plasmonically heated gold nanoparticles. Trends Biotechnol 24(2):62-67

Proske D, Blank M, Buhmann R, Resch A (2005) Aptamersbasic research, drug development, and clinical applications. Appl Microbiol Biotechnol 69(4):367-374

Sokolov K et al (2003a) Optical systems for in vivo molecular imaging of cancer. Technol Cancer Res Treat 2(6):491504

Sokolov K et al (2003b) Real-time vital optical imaging of precancer using anti-epidermal growth factor receptor antibodies conjugated to gold nanoparticles. Cancer Res 63(9):1999-2004

Storhoff JJ, Elghanian R, Mucic RC, Mirkin CA, Letsinger RL (1998) One-pot colorimetric differentiation of polynucleotides with single base imperfections using gold nanoparticle probes. J Am Chem Soc 120(9):1959-1964

Thomas M, Klibanov AM (2003) Conjugation to gold nanoparticles enhances polyethylenimine's transfer of plasmid DNA into mammalian cells. Proc Natl Acad Sci USA 100(16):9138-9143

Tkachenko AG et al (2003) Multifunctional gold nanoparticlepeptide complexes for nuclear targeting. J Am Chem Soc 125(16):4700-4701

Tombelli S, Minunni M, Mascini M (2005) Analytical applications of aptamers. Biosens Bioelectron 20(12):24242434

Tsoli M, Kuhn H, Brandau W, Esche H, Schmid G (2005) Cellular uptake and toxicity of AU(55) clusters. Small 1(8-9):841-844

Tuerk C, Gold L (1990) Systematic evolution of ligands by exponential enrichment—rna ligands to bacteriophage-T4 DNA-polymerase. Science 249(4968):505-510

Yelin D, Oron D, Thiberge S, Moses E, Silberberg Y (2003) Multiphoton plasmon-resonance microscopy. Opt Express 11(12):1385-1391

Yguerabide J, Yguerabide EE (1998) Light-scattering submicroscopic particles as highly fluorescent analogs and their use as tracer labels in clinical and biological applications: I. Theory Anal Biochem 262(2):137-156

Zhi PX, Qing HZ, Gao QL, Ai BY (2006) Inorganic nanoparticles as carriers for efficient cellular delivery. Chem Eng Sci 61(3):1027-1040 